\title{
Structural Use of Expanded Polystyrene Concrete
}

\author{
Adeniran Jolaade ADEALA \\ Olugbenga Babajide SOYEMI ${ }^{1}$ \\ Department of Civil Engineering, \\ The Federal Polytechnic Ilaro, Ogun State Nigeria
}

\begin{abstract}
Expanded polystyrene (EPS) wastes are generated from industries and post-consumer products. They are non-biodegradable but are usually disposed by burning or landfilling leading to environmental pollution. The possibility of using EPS as partial replacement for fine aggregates in concrete has generated research interests in recent times. However, since the physical and mechanical properties of EPS are not like those of conventional fine aggregates, this study is focussed on the use of EPS as an additive in concrete while keeping other composition (sand and granite) constant. Expanded polystyrene was milled, the bulk density of EPS was $10.57 \mathrm{~kg} / \mathrm{m}^{3}$ and particle size distributions were determined. Engineering properties of expanded polystyrene concrete were determined in accordance with BS 8110-2:1985. The result showed that the amount of expanded polystyrene incorporated in concrete influence the properties of hardened and fresh concrete. The compressive strengths of $17.07 \mathrm{MPa}$ with $5 \%$ expanded polystyrene concrete at 28 days for example can be used as a lightweight concrete for partitioning in offices. Incorporating expanded polystyrene granules in a concrete matrix can produce lightweight polystyrene aggregate concrete of various densities, compressive strengths, flexural strengths and tensile strengths. In conclusion, this reduces environmental pollution, reduction in valuable landfill space and also for sustainability in construction companies.
\end{abstract}

Keywords:- Polystyrene, Strength, Flexural, Bulk density, Absorption.

\section{INTRODUCTION}

Materials selection cannot be overlooked or take with negligence in the design and construction of any engineering structures (Dahunsi, 2012). Engineers are daily involved with materials/substances in manufacturing, selection, usage and analyses. A number of significant decisions are made when choosing materials to be combined into a design, which include whether the materials can be formed into the precise and desired shape, dimensional tolerance and maintain the desired shape during usage, whether the essential properties can be attained and maintained during usage. It also includes whether the material is compatible with others, is it recyclable? Can it cause environmental problems? And is the material economically useful? (Askeland, 1996). Wastes are generated from industries and post-consumer products such as expanded polystyrene used for packaging products which are non-biodegradable but are usually disposed by burning or landfilling leading to environmental pollution. In order to minimize the risk of environmental pollution expanded polystyrene can be incorporated into concrete to produce lightweight concrete (Clarke, 1993; Jones \& McCarthy, 2005; Mydin \& Wang, 2012)

Polystyrene was accidentally discovered in 1839 by Eduard Simon, a Berlin apothecary (Makai, et al., 2016; Baker, 2018) and named styrol. In 1845, English chemist John Blyth and German chemist August Wilhelm von Hofmann developed a substance named metastyrol which has the same alteration as that of styrol but was produced in the a vacuum (Blyth and Hofmann, 1845). The precise formation of metastyrol from styrol was identified in 1866 as a polymerization process (Berthelot, 1866). Expanded polystyrene is a steady low-density foam and comprises discrete air voids in a polymer medium. The polystyrene beads can effectively be combined in mortar or concrete mix to make lightweight concrete with a wide variety of density (Ravindrarajah \& Tuck, 1994). Nevertheless, polystyrene beads have two main weaknesses that constrains the usage and commercialisation of EPS concrete and these are (i) they are tremendously light, with a density as low as 12 to $20 \mathrm{~kg} / \mathrm{m}^{3}$, which may cause isolation in mixing, and (ii) they are hydrophobic. Therefore, its surface may require chemical treatment (Chen \& Liu, 2004). In some reports, bonding additives were recommended, but these are expensive, thus making the EPS concrete costly (Bagon \& Frondistou-Yannas, 1976; Perry, et al., 1991; Chen \& Liu, 2004).

According to Shanghai in 1999, the EPS concrete having a density ranging from $800 \mathrm{~kg} / \mathrm{m}^{3}$ to $1800 \mathrm{~kg} / \mathrm{m}^{3}$ and a compressive strength ranging from $10 \mathrm{MPa}$ to $25 \mathrm{MPa}$ can be accomplished by substituting coarse and fine aggregate with EPS beads and this were corroborated by other researchers (Newman \& Owens, 2003; Aslam, et al., 2016; Chaukura, et al., 2016). In the work of Mbadike and Osadebe, in 2003 on the technical note on consequence of adding EPS aggregate pellets in concrete matrix, the result showed that the compressive strength for 5 to $40 \%$ replacement of coarse aggregate with polystyrene pellets ranges from 5.05 to $31.75 \mathrm{MPa}$ when compared with 23.59 to $36.08 \mathrm{MPa}$ of the $0 \%$ replacement (control test). The workability for 5 to $40 \%$ replacement of coarse aggregate with polystyrene ranges from $15 \mathrm{~mm}$ to $63 \mathrm{~mm}$ compared to $10 \mathrm{~mm}$ for the $0 \%$ replacement (control test). In this study, discarded expanded polystyrene will be used as an addictive to concrete and its effects on concrete was investigated. 


\section{MATERIALS AND METHODS}

This project work entails both Field and laboratory work. The Field work required sourcing for aggregates (Sharp sand and granite) and expanded polystyrene beads. The laboratory experiments were carried out in Civil Engineering Soil Mechanics Laboratory University of Ibadan, Ibadan Oyo state.

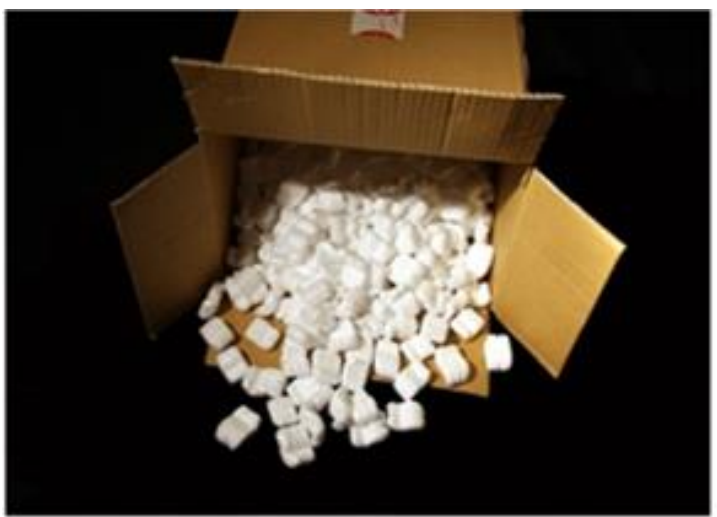

The EPS beads packaging waste were collected from Laboratory testing machine bought for Civil Engineering Department University of Ibadan. The EPS beads were reduced in size by Hammer milling machine in Thermodynamic Mechanical Laboratory University of Ibadan so as to increase the surface area thereby increasing rate of reaction with concrete. Milled EPS were added in steps of $15 \mathrm{~g}$ between 0 and $90 \mathrm{~g}$ were added to concrete of mix design ratio of 1: 1.59:3.14 with water cement ratio of 0.38 .

Fig 1:- Collection of discarded EPS beads and milled expanded polystyrene

\begin{tabular}{|c|c|c|c|c|c|c|c|}
\hline & \multicolumn{7}{|c|}{ Mix (\%) } \\
\hline & 0 & 5 & 10 & 15 & 20 & 25 & 30 \\
\hline Cement & 15 & 15 & 15 & 15 & 15 & 15 & 15 \\
\hline FA & 23.85 & 23.85 & 23.85 & 23.85 & 23.85 & 23.85 & 23.85 \\
\hline C.A & 47.10 & 47.10 & 47.10 & 47.10 & 47.10 & 47.10 & 47.10 \\
\hline EPS & 0.000 & 0.015 & 0.030 & 0.045 & 0.060 & 0.075 & 0.090 \\
\hline Water & 5.7 & 5.7 & 5.7 & 5.7 & 5.7 & 5.7 & 5.7 \\
\hline
\end{tabular}

Table 1:- Batch Weight of materials $(\mathrm{kg})$ for each mix

The concrete cubes, prisms and cylinders were cured according to ACI (1992) and compressive, flexural and spilt tensile strengths were carried out on cured cubes at 7, 14, 21 and 28days.Also 28 days water absorption tests were carried on concrete cube. Cube $(150 \mathrm{~mm} \times 150 \mathrm{~mm} \times 150 \mathrm{~mm})$, prism $(100 \mathrm{mmx} 100 \mathrm{~mm} \times 500 \mathrm{~mm})$ and cylinder (100mm diameter and 200mm height) were tested using electronic digital testing machine as per the BS EN 12390-3:1983, BS EN 12390-5:2009 BS EN 12390-6:2009, (BS813-2: 1995 and BS EN 1097-3) requirements respectively. In this research 28 days curing specimen were discussed.

\section{RESULT AND DISCUSSION}

Sieve analysis was carried out on the EPS and the result presented in Figure 2

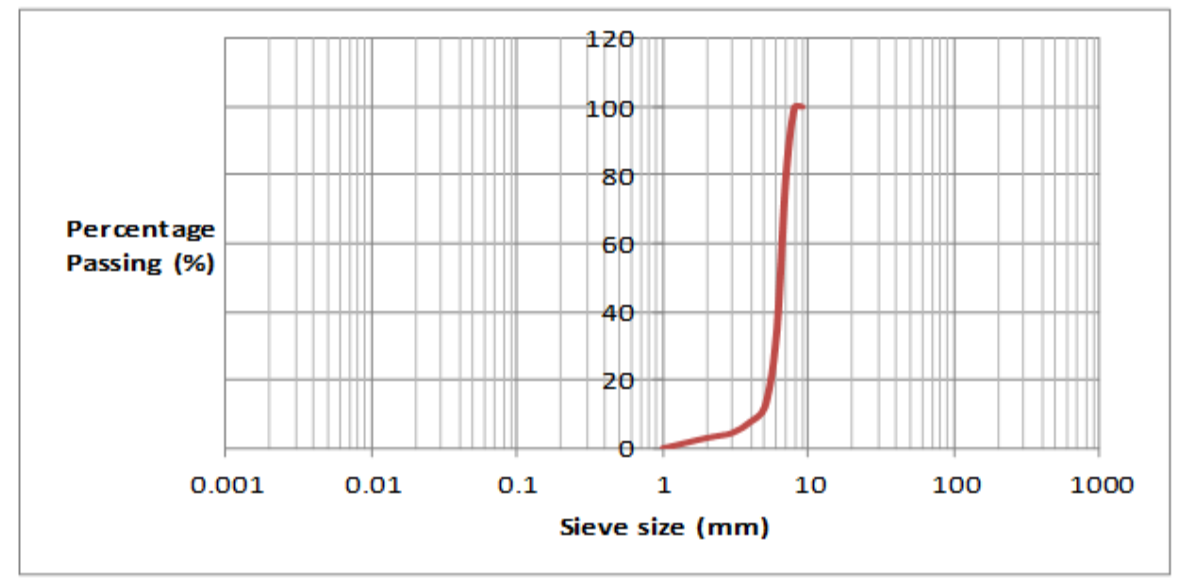

Fig 2:- Particle size distribution curve for milled expanded polystyrene. 
From the curve in Figure 2,

$$
\begin{aligned}
& D_{10}=5 \\
& D_{30}=6 \\
& D_{60}=7
\end{aligned}
$$

Coefficient of uniformity (curvature) $\mathrm{Cu}=\mathrm{D}_{60} / \mathrm{D}_{10}$ $\mathrm{C}_{\mathrm{u}}=7 / 5=1.4<3$ (uniform EPS))

Coefficient of gradation (curvature) $\mathrm{Cc}=\left(\mathrm{D}_{30}\right)^{2} / \mathrm{D}_{60} . \mathrm{D}_{10}$ $\mathrm{C}_{\mathrm{c}}=6^{2} / 7.5$

$$
=1.03 \text { lies between } 0.5 \text { and } 2 \text { (well graded EPS) }
$$

Interpretation: Expanded polystyrene is uniformly and well graded according to BS 1377: Part2: 1990.

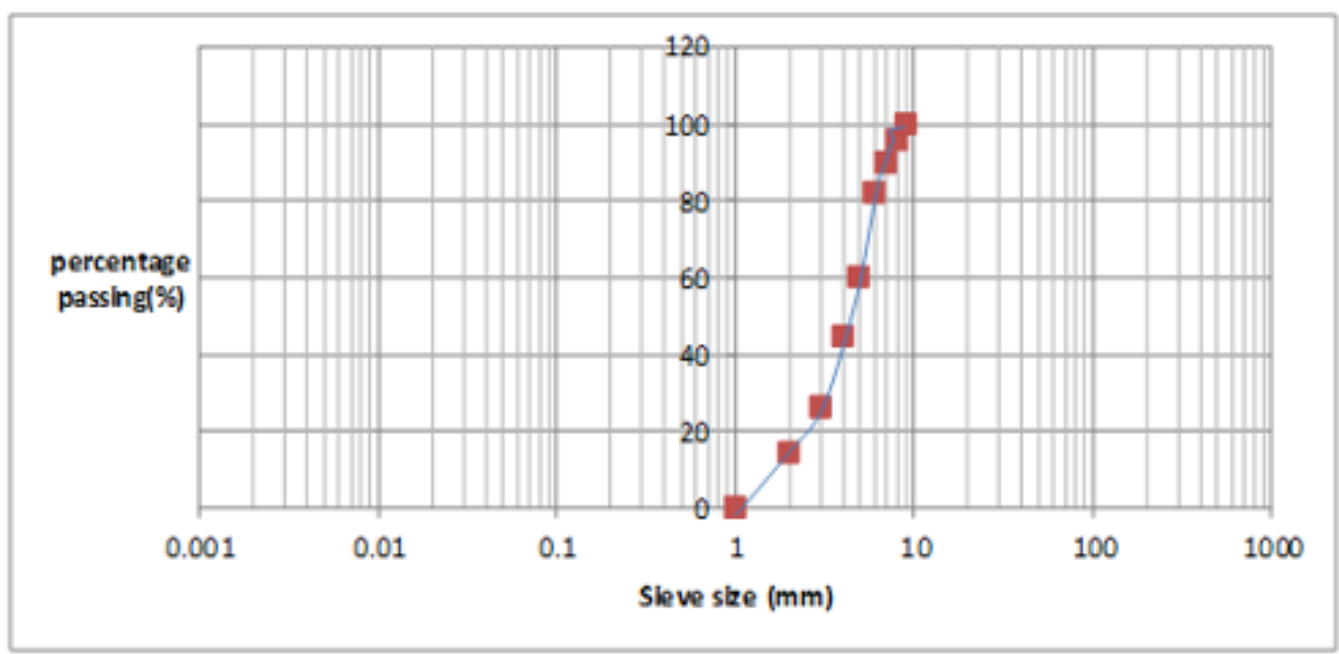

Fig 3:- Particle size distribution curve for fine aggregate (sand)

Figure 3 shows the particle size distribution of fine aggregate and from the curve, the following were determined:

$$
\begin{aligned}
& \mathrm{D}_{10}=1.8 \\
& \mathrm{D}_{30}=3.6 \\
& \mathrm{D}_{60}=5.1
\end{aligned}
$$

Coefficient of uniformity (curvature) $\mathrm{Cu}=\mathrm{D}_{60} / \mathrm{D}_{10}$ $\mathrm{C}_{\mathrm{u}}=5.1 / 1.8=2.8<3$ (uniformly graded)

Coefficient of gradation (curvature) $\mathrm{Cc}=\left(\mathrm{D}_{30}\right)^{2} / \mathrm{D}_{60} . \mathrm{D}_{10}$ $\mathrm{C}_{\mathrm{c}}=3.6^{2} /(5.1)(1.8)$

$=1.4$ lies between 0.5 and 2 (well graded)

Interpretation: Expanded polystyrene is uniformly and well graded according to BS 1377: Part2: 1990. 


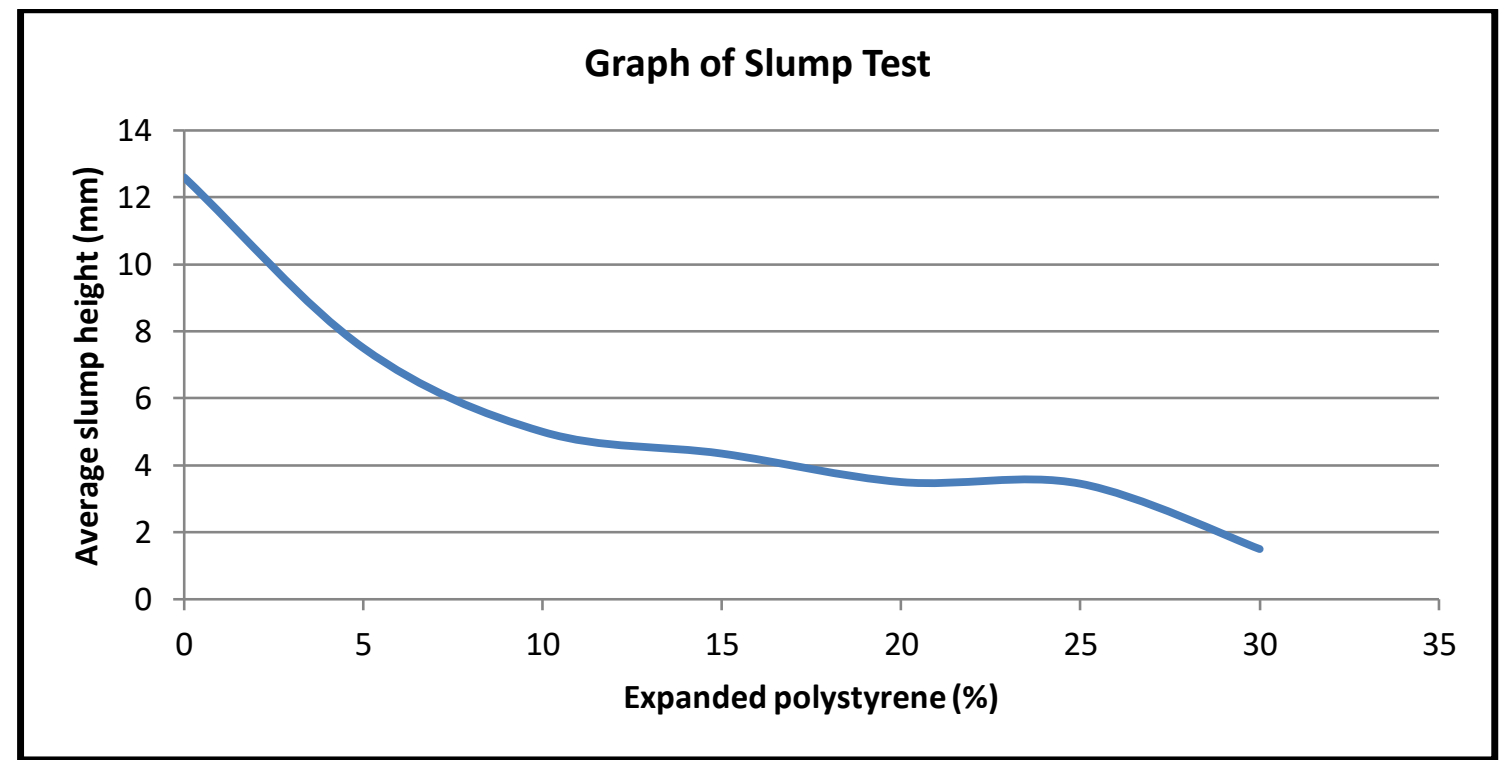

Fig 4:- Graph of slump against \% expanded polystyrene concrete specimen.

It was observed from Figure 4 that the slump height decreases as the expanded polystyrene increases in the concrete i.e. the higher the EPS in concrete the less workable the concrete.

\begin{tabular}{|c|c|c|c|c|c|c|c|}
\hline Days & $0 \%$ & $5 \%$ & $10 \%$ & $15 \%$ & $20 \%$ & $25 \%$ & $30 \%$ \\
& & EPS & EPS & 10.30 & 10.97 & 5.69 & 5.49 \\
EPS
\end{tabular}

Table 2:- Average compressive strength of EPS concrete with percentage of dosage of EPS

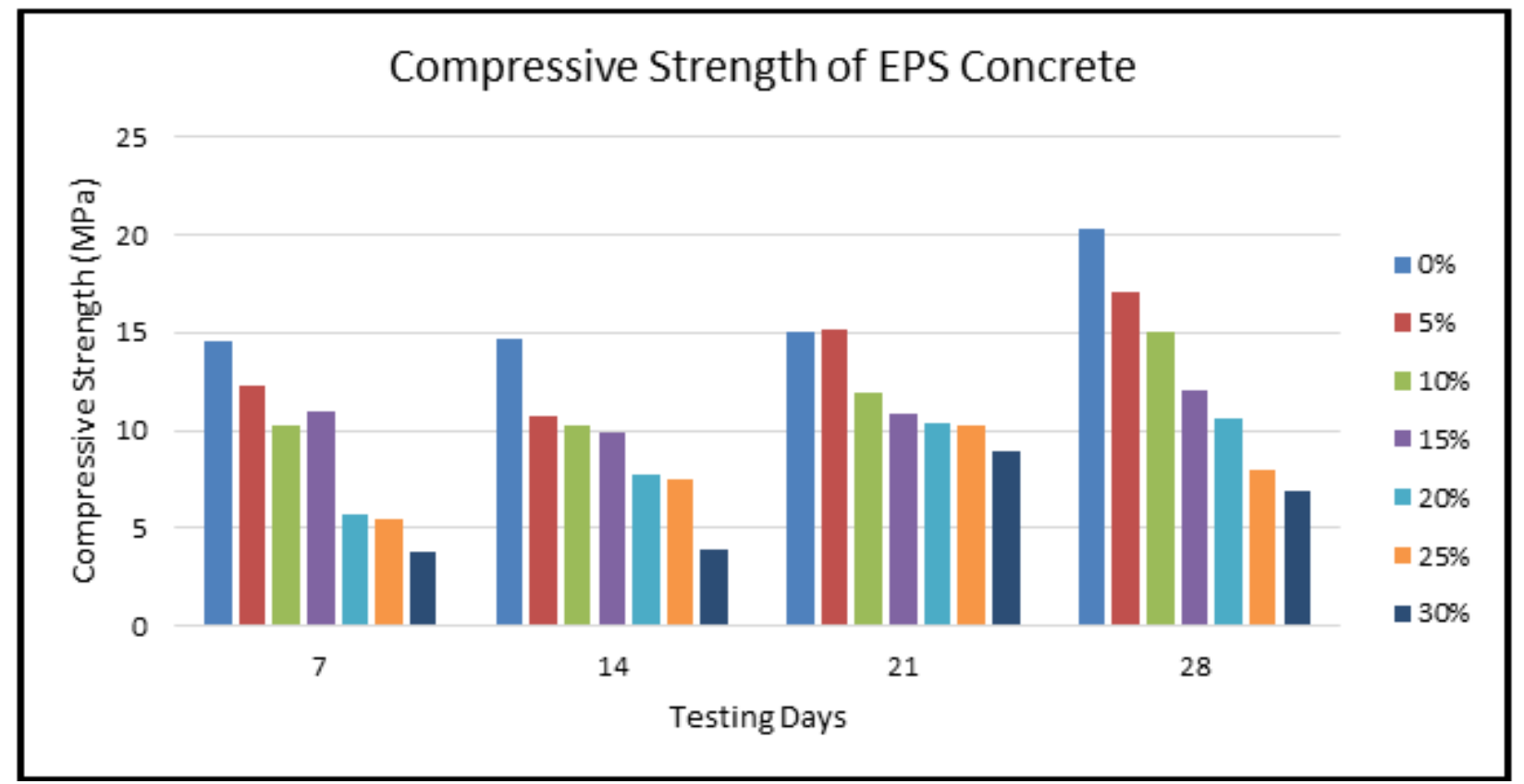

Fig 5:- Average compressive strength of EPS concrete with percentage of dosage of EPS

Table 2 and Figure 5 gave the average compressive strength of the EPS concrete in 7, 14, 21 and 28 days. It could be seen that the higher the dosage of EPS, the lower the strength. Also, as the days goes by, the EPS concrete gains more strength. 


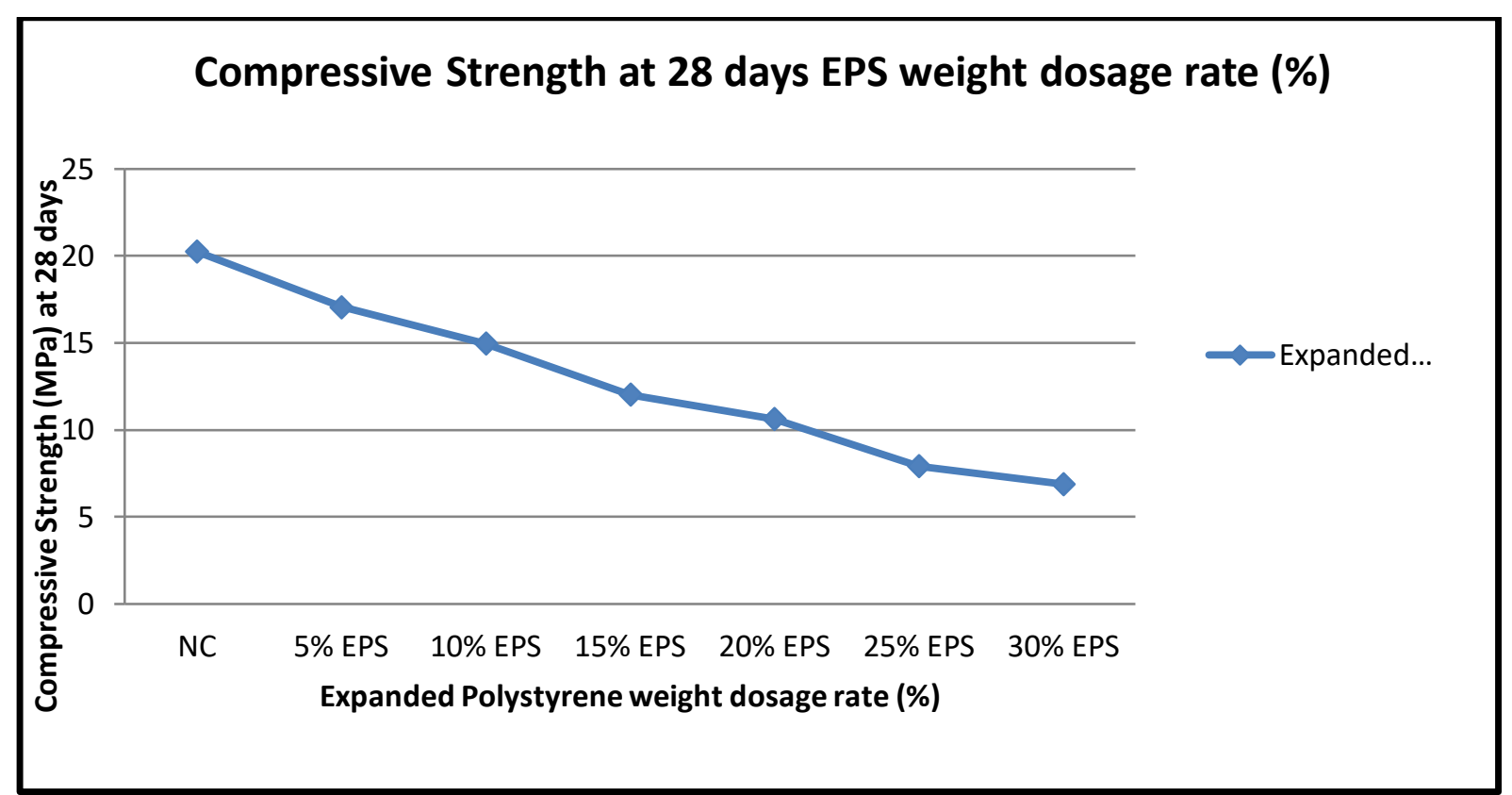

Fig 6:- Compressive Strength development at 28 days against the EPS weight dosage

A critical look at the strength in the 28th day tests show that the EPS concrete containing 5\% EPS has the maximum compressive strength of $17.07 \mathrm{MPa}$ and has a margin of $3.18 \mathrm{MPa}(15.7 \%)$ below control. After $5 \%$ the compressive strength is declining as the EPS is increasing in concrete matrix.

The flexural strength tests were carried out using a beam $(150 \times 150 \times 600 \mathrm{~mm})$ supported at $50 \mathrm{~mm}$ to the edge with $500 \mathrm{~mm}$ clear span. The result after 28 days is presented in Figure 7. It also shows that as the EPS dosage increases, the flexural strength decreases.

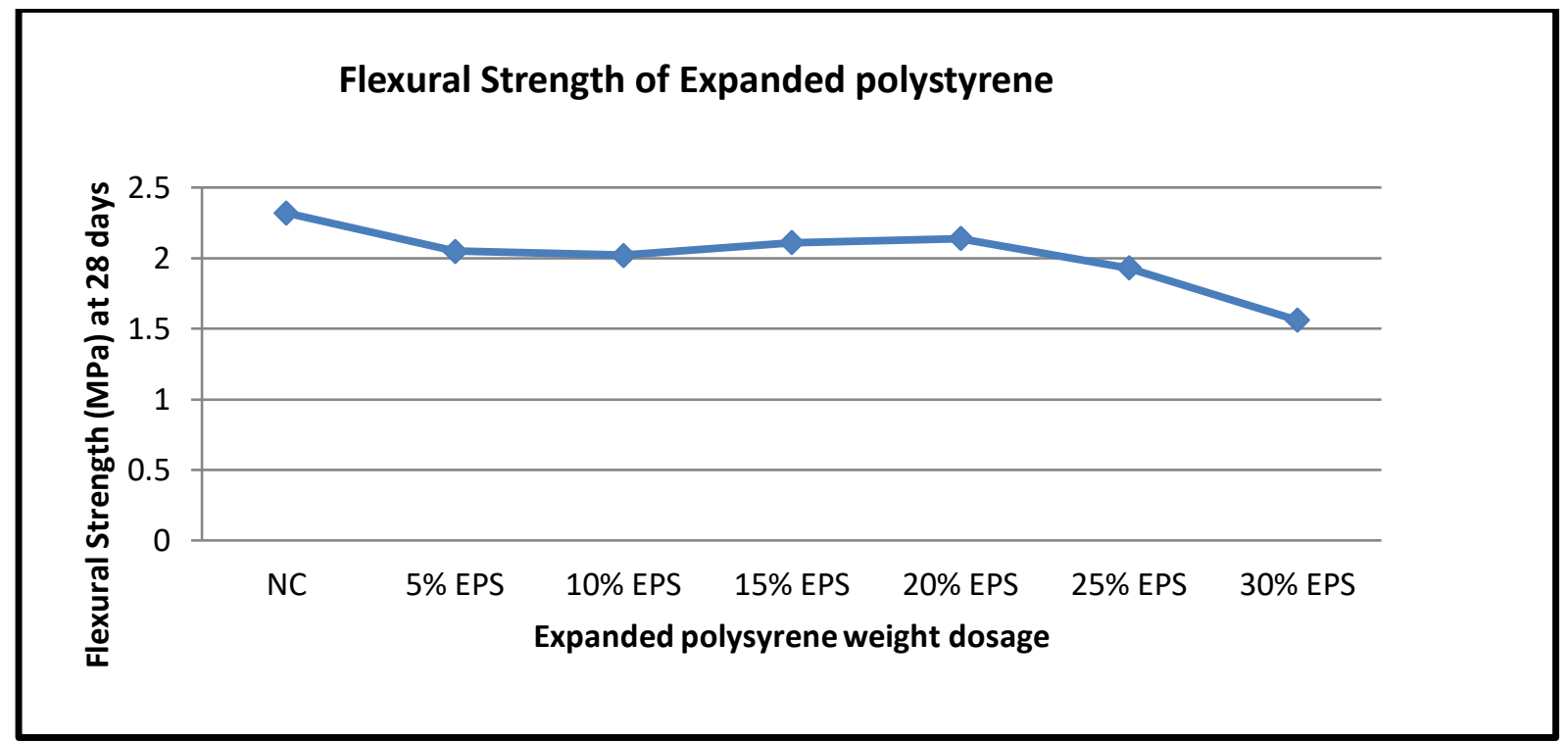

Fig 7:- Graph of flexural strength at 28 days against the expanded polystyrene weight dosage.

Likewise, the split tensile test was carried out to determine the tensile strength of the EPS concrete and result presented in Figure 8. There was a rise in the value of the tensile strength from the control to the highest value at $10 \%$ EPS concrete (2.28MPa) and then a fall in the value to least value of $1.25 \mathrm{MPa}$ for $30 \%$ EPS concrete. This can be deduced to be because of the hydrophobic nature of the EPS. The larger the amount, the less the cohesiveness of the material, thus shearing of at high dosage. 


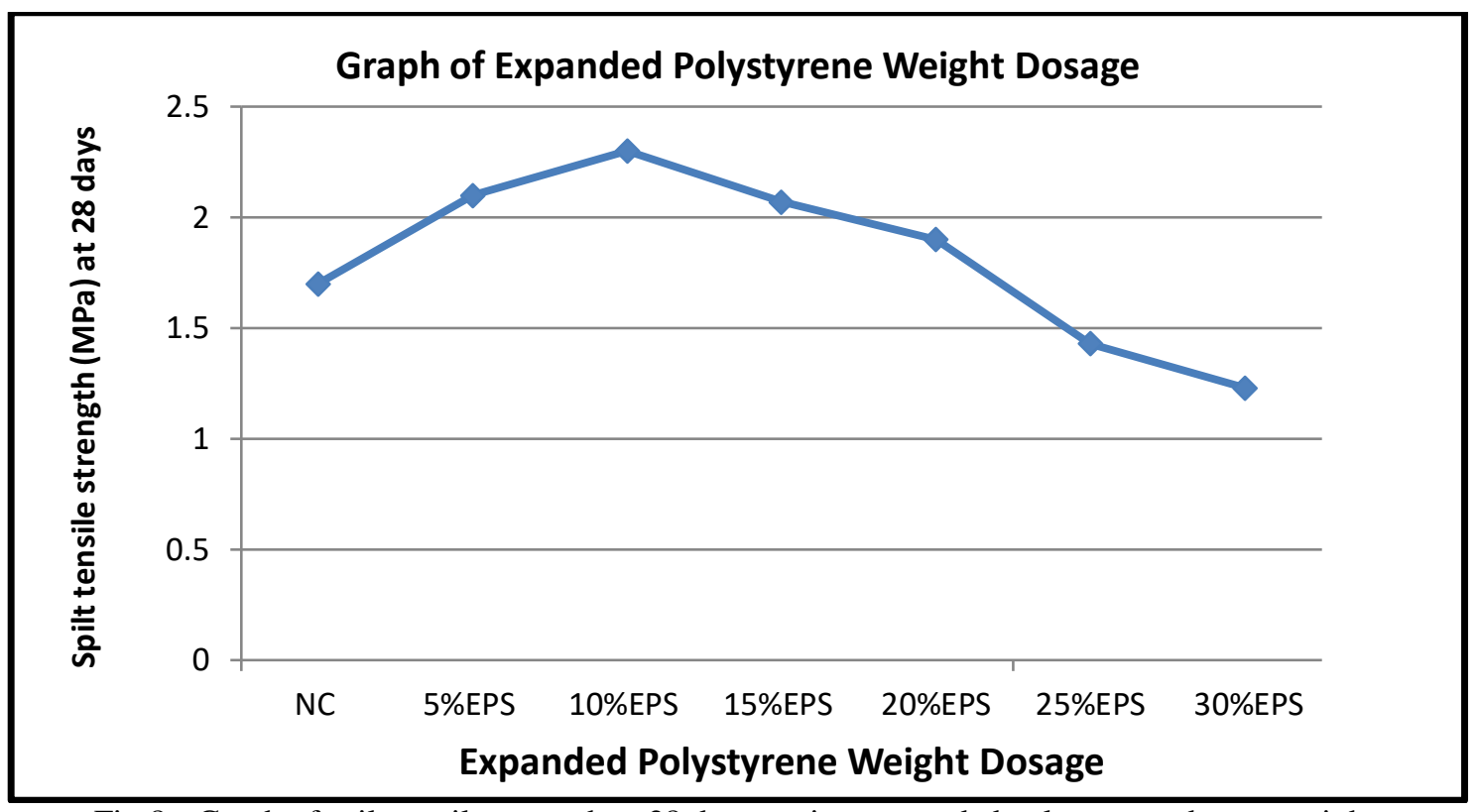

Fig 8:- Graph of spilt tensile strength at 28 days against expanded polystyrene dosage weight.

Further statistical analysis was carried out on the results of the compressive strength at the 27th day, to determine the relationship between the EPS dosage and the compressive strength. A linear equation was derived from a nest fit graph using Microsoft Excel in Figure 9 and stated below:

$$
\begin{gathered}
y=-0.4476 x+19.543 \\
\text { where } \quad \begin{array}{l}
y-\text { compressive strength }(\mathrm{MPa}) \\
\mathrm{x}-\operatorname{EPS} \text { dosage }(\%)
\end{array}
\end{gathered}
$$

And the correlation factor $\mathrm{R}^{2}=0.9861$. There is strong correlation between compressive strength and \% EPS weight dosage.

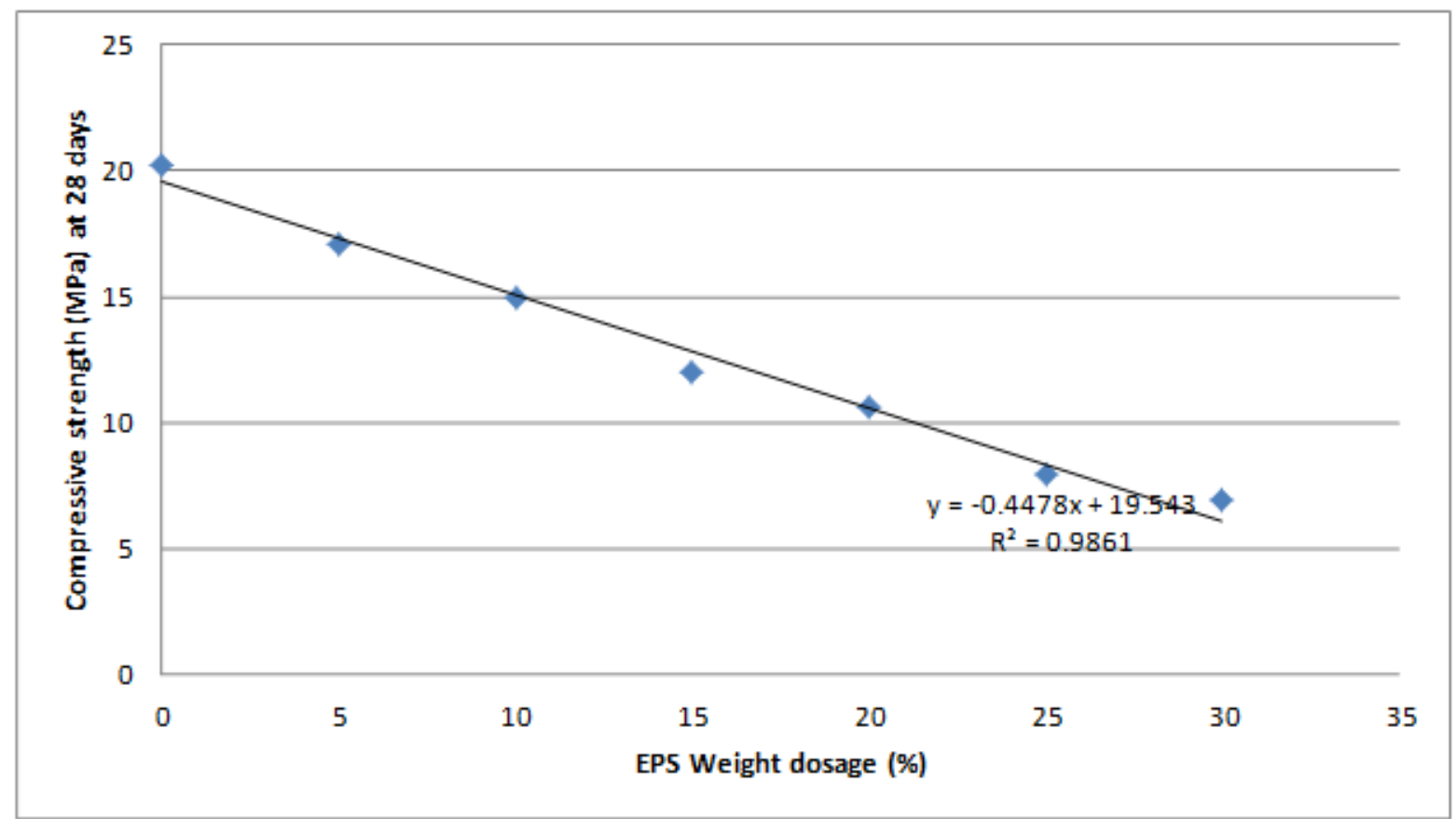

Fig 9:- Regression analysis between compressive strength and tensile strength at 28 days.

Water absorption test was carried in accordance to (BS 813-2; 1995). The EPS concrete has its water absorption varied from 1.11 to $1.55 \%$ which is good water absorption which according to Concrete Society, (Parrott, 1985) the quality of concrete is considered good if the water absorption is between $0.89 \%$ and $3 \%$. 
ISSN No:-2456-2165

\begin{tabular}{|c|c|c|c|c|c|}
\hline $\begin{array}{c}\text { Mix } \\
(\%)\end{array}$ & $\begin{array}{c}\text { Unit weight } \\
(\mathrm{kg} / \mathrm{m} 3)\end{array}$ & $\begin{array}{c}\text { Dry Weight } \\
(\mathrm{g})\end{array}$ & $\begin{array}{c}\text { Wet Weight } \\
(\mathrm{g})\end{array}$ & $\begin{array}{c}\text { Water loss } \\
(\mathrm{g})\end{array}$ & \% Water gain \\
\hline 0 & 2370 & 8000 & 7800 & 200 & 2.56 \\
\hline 5 & 2340 & 7900 & 7800 & 100 & 1.28 \\
\hline 10 & 2326 & 7850 & 7730 & 120 & 1.55 \\
\hline 15 & 2311 & 7800 & 7700 & 100 & 1.30 \\
\hline 20 & 2252 & 7600 & 7517 & 83 & 1.11 \\
\hline 25 & 2222 & 7500 & 7400 & 100 & 1.35 \\
\hline 30 & 2193 & 7400 & 7300 & 200 & 1.37 \\
\hline
\end{tabular}

Table 3:- Water absorption for expanded polystyrene concrete at 28 days.

Increase in expanded polystyrene lead to reduction in water absorption of concrete. Expanded polystyrene also formed part of the aggregate and act as a filler thus having a less voids as compared to concrete without expanded polystyrene.

\section{CONCLUSIONS}

The research investigated the effect of EPS in structural concrete. The effects of EPS on the mechanical properties, durability and workability of the concrete were investigated. From the results and analysis of this research, it was observed that as the volume of the EPS dosage increases, the workability decreases, the compressive strength decreases, the flexural strength decreases, the tensile strength increases up to 10\% EPS and then decrease, thus making the EPS concrete a weak concrete. It can be used for low-strength components of a structure.

\section{REFERENCES}

[1]. Askeland, D. R. (1996). Introduction to materials. In The science and engineering of materials (pp. 217). Springer, Boston, MA.

[2]. Aslam, M., Shafigh, P., Jumaat, M. Z., \& Lachemi, M. (2016). Benefits of using blended waste coarse lightweight aggregates in structural lightweight aggregate concrete. Journal of Cleaner Production, 119, 108-117.

[3]. ACI 308-92 (1992) Standard practice for curing concrete.

[4]. Bagon, C. \& Frondistou-Yannas S. (1976). Marine floating concrete made with polystyrene beads, Mag. Concr. Res. 28. 225-229.

[5]. Baker I. (2018) ABS Plastics. In: Fifty Materials That Make the World. Springer, Cham

[6]. Berthelot, M. (1866). Sur l'origine des carbures et des combustibles minéraux (On the origin of carbides and mineral fuels) Ann. Chim. et Phys., 4e série, 9, 481-483.

[7]. Blyth, J., \& Hofmann, W. A., (1845). "Ueber das Stryol und einige seiner Zersetzungsproducte" (On styrol and some of its decomposition products)", Annalen der Chemie und Pharmacie, Vol. 53 (3), pp. 289-329.
[8]. British Standard 1377. 1990. Methods of Testing Soil for Civil Engineering Purposes. British Standards Institute, London.

[9]. British Standard 8110-2:1985 Structural use of concrete. Part 2 - Code of practice for special circumstances. British Standards Institute, London.

[10]. Chen, B., \& Liu, J. (2004). Properties of lightweight expanded polystyrene concrete reinforced with steel fiber. Cement and Concrete Research,34(7), 12591263.

[11]. Clarke, J.L. (1993), Structural lightweight aggregate concrete, published by: Blackie Academic\&Professional, an imprint of Chapman \& Hall, Glasgow, first edition, 1-41.

[12]. Dahunsi, B.I.O. (2012) Advanced Materials for construction for composite materials, University of Ibadan.

[13]. EN, B. (2002). 12390-3. Testing hardened concrete; part 3: compressive strength of test specimens. British Standards Institution.

[14]. EN, B. (2009). 12390-5: 2009. Testing hardened concrete. Flexural strength of test specimens British Standards Institution, London.

[15]. EN, B. (2009). 12390-6 (2009). “Testing Hardened Concrete. Tensile Splitting Strength of Test Specimens". British Standard Institution, London.

[16]. Jones, M. R., \& McCarthy, A. (2005). Preliminary views on the potential of foamed concrete as a structural material. Magazine of concrete research, 57(1), 21-31.

[17]. Makai, A., Kiss, J., \& Mucsi, G. (2016). The Possibilities of Polystyrene Waste Recycling. In $X X X$. microCAD International Multidisciplinary Scientific Conference.

[18]. Mbadike C.J \& Osadebe O.B, 2003 Technical note on expanded polystyrene aggregate granules in concrete matrix.

[19]. Mydin, M. A. O., \& Wang, Y. C. (2012). Mechanical properties of foamed concrete exposed to high temperatures. Construction and Building Materials, 26(1), 638-654.

[20]. Chaukura, N., Gwenzi, W., Bunhu, T., Ruziwa, D. T., \& Pumure, I. (2016). Potential uses and value-added products derived from waste polystyrene in developing countries: A review. Resources, Conservation and Recycling, 107, 157-165. 
[21]. Newman, J., \& Owens, P. (2003). Properties of lightweight concrete. Advanced concrete technology, 3, 1-29.

[22]. Parrott, L. J. (1985). Effect of changes in UK cements upon strength and recommended curing times. Concrete (London), 19(9).

[23]. Perry, S.H, Bischoff, P.H, \&. Yamura, K (1991), Mix details and material behaviour of polystyrene aggregate concrete, Mag. Concr. Res. 43 71- 76.

[24]. Ravindrarajah, R. S., \& Tuck, A. J. (1994). Properties of hardened concrete containing treated expanded polystyrene beads. Cement and Concrete Composites, 16(4), 273-277.

[25]. Shanghai J (1999) Technical Journal on effect of EPS on Concrete, China. 